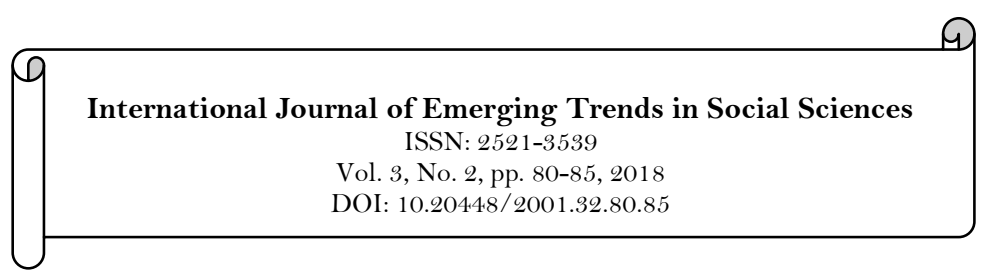

\title{
Layout Criteria for Enhancing Indonesian SMEs Production's Performance
}

\author{
Anton Mulyono Azis ${ }^{1}$ \\ ${ }^{1}$ Ekuitas Business School, Bandung-Indonesia. \\ Email:anton.mulyono@eknitas.ac.id
}

\begin{abstract}
A reliable layout will improve the process effectiveness and lead the production performance at an excellent level. Unfortunately, SMEs in Indonesia have not realized how important it is, and put layout decisions just as an alternative operating decision to improve company's performance. This study aims to identify reliable layout criteria that should be applied by SMEs production managers in Indonesia to improve their production performance. This research used quantitative methods by investigating 276 SMEs in West Java - Indonesia. The result found that related to the layout design; technology, process, facilities, and product type are the most important factors affecting company's production performance. The four factors are then derived into appropriate criteria that can be applied to Indonesian SMEs. Two kinds of further research can be continued by deepening each of the generated criteria and their application in the specific SME so that the results will better reflect the conditions of SME's production layout in Indonesia.
\end{abstract}

\section{Introduction}

The workspace or workshop area limitation for Indonesian SMEs has become the common barrier and difficulty for redesigning its factory layout (Irjayanti, Azis, \& Sari, 2016). This redesigning process is done for gaining a competitive edge in the domestic or global market (Ramli \& Chen, 2014). However, this situation often makes production costs swell and indirectly increases the ineffectiveness of materials handling activities (Fitriani, Prakoso, \& Azis, 2015). This finding in line with the research of Khan and Tidke (2013) and (Kumar, Verma, Onkar, Singh, \& Katiyar, 2016) which states there is an imbalance of the area required for machinery and facilities arrangement in the factory and it resulted to the failure of increasing the company's productivity.

Furthermore, another common problem in most Indonesian SMEs is an unsatisfactory working environment that has an impact on the high number of workplace accidents and the deterioration of worker's health. This is confirmed by a study by Vasconcelos and Junior (2015) that stated good working condition will reduce the accident rate, with a reduction of losses in productivity and the workers' quality of life. As also stressed by Zakaria, Mansor, and Abdullah (2012) that one of main working place accident is poor working place conditions, therefore it is important to give more attention to design stage within the working environment. Several other common problems that occur when redesigning the layout of Indonesian SMEs are layout mismatch with the dynamic changes of product design, product variations, changing levels or volume of demand, waste of material handling costs, and the obsolescence of used machinery or facilities. These things lead to declining the company's operations performance (Azis \& Azis, 2013).

Furthermore, from the review of relevant scientific articles, the discussion on layout criteria in each factors such technology, product, process, facility, or other factors, is very limited, especially facility layout for the small and medium company (Susanto \& Azis, 2017). The current facility layout research mainly emphasizes layouts using various methods, but does not specifically address what criteria should be met when redesigning the layout (see. (Corry \& Kozan, 2004; Irjayanti \& Azis, 2013; Naik \& Kallurkar, 2016)). In addition, the topics also discussing more the impact of poorly implemented layouts, instead of how to manage the reliable layout (Irjayantis \& Azis, 2017). Hence based on the business phenomenon and the research gaps, the purpose of this study is to identify the reliable layout criteria that should be applied by SMEs production managers in Indonesia to improve their long-term production performance. 


\section{Literature Review}

The layout of small businesses basically is the arrangement of physical facilities by dividing the production processes into small autonomous production units due to space constraints in producing goods. Theoretically, this layout type can be categorized into layouts for small plants (Susanto \& Azis, 2017). Several common problems often occured for designing layout for small factory, i.e. difficulties in locating the facilities (e.g., machines, departments) in a plant (Chikwendu \& Okechukwu, 2016; Drira, Pierreval, \& Hajri-Gabouj, 2007) ineffective material flows (Sharma, Singh, \& Singhal, 2013) unflexible layout as difficult and slow in changing the production type (De Carlo, Arleo, Borgia, \& Tucci, 2013) critical and complex task due to the increasing demands (Azise, Simatupang, Wibisono, \& Basri, 2013; Benabes, Poirson, \& Bennis, 2013) and hard modules of unequal dimensions in open space (Tasadduq, Imam, \& Ahmad, 2015).

The main criteria that must be considered in the small factory business layout is related to product, process, capacity, and technology (Susanto \& Azis, 2017) for reaching the most optimal cost (Kovacs \& Kot, 2017; Singh \& Singh, 2015) and for being on-time production processes as well (Bhowmik, 2008; Ojaghi, Khademi, Yusof, Renani, \& Syed-Helmi, 2015). Those main criteria should be implemented with some principles, such: total integrated principles (Dias, Pereira, Vik, \& Oliveira, 2012) minimum moving distance (Tao, Wang, Qiao, \& Tang, 2012) smooth working flow or simple flowchart processes (Belic, Kunica, Opetuk, \& Dukic, 2018) working with safe and secure condition (Fei, Feng, \& Xia, 2011) and flexibility (Kareem, Oke, \& Lawal, 2013).

Meanwhile, for assessing the performance of one factory's layout, there are several principles that should be considered (see. (Azis, 2011; Modrak, Soltysova, \& Bednar, 2017; Silva, Mendes, \& Ramos, 2016)). Modrak et al. (2017) stated that several characteristics in the production process related product or process layout will impact to the performance of production, i.e. throughput rate of parts per minute and operational complexity, while other researchers mentioned about the street frontage or access of person or goods and the economic of spacing utilization (Silva et al., 2016). In general, the layout related production performance can be assessed by following 7 principles (Susanto \& Azis, 2017) i.e. the minimum distance, minimum of usage space, smooth working sequence, compactness, safety job, the employee satisfaction, and optimum investment.

\section{Research Methodology}

This research used quantitative methods by investigating 276 SMEs in West Java - Indonesia. Data is obtained through direct observation at the factory of SMEs as primary data and the collection of company's related layout documents as secondary data. Observations were made to see the composition of the area of a single floor or multilevel plant used, the production facilities placement, the movement of people and working tools, the storage of goods -especially raw materials and finished goods, the safety and security level of the factory workers, and the working satisfaction of the workers. In addition to the primary data, interview techniques are also conducted to the workers. This technique is done to explore the problems that often occur in the production process, especially related to the layout of the factory, and also explored the extent of the worker level satisfaction on the arrangement of factory area and the use of factory tools.

Meanwhile, the secondary data are documents taken from the company, related to layout data such as layout plan used, workspace specification, working accident record and the cause of each accident, and the worker's complaints and difficulties experienced. Other secondary data included company investment records related to land, machinery, and facilities, for factory development or factory layout redesign. This data is necessary to measure the extent to which investment rates and factory flexibility could meet the consumer demand

Furthermore, the validity and reliability of the research (Yin, 2014) are confirmed through selected observations and documents, as well as the secondary documents that have been declared true and approved. While the interview session is done to the right key person to increase the level of internal validity. While external validity, confirmed through the steps according to research procedures, so there is some understanding between the researcher and the research objects, both the interviewed parties and other related parties. While the reliability of the research is ensured through the review of all data collected by some appropriate analytical process, so that it can be avoided biased, and increases the objectivity as the final result.

\section{Results and Analysis}

The result found that related to the layout design; technology, process, facilities, and product type are the most important factors affecting company's production performance (Susanto \& Azis, 2017). Figure 1 describes the percentages of each factor. 


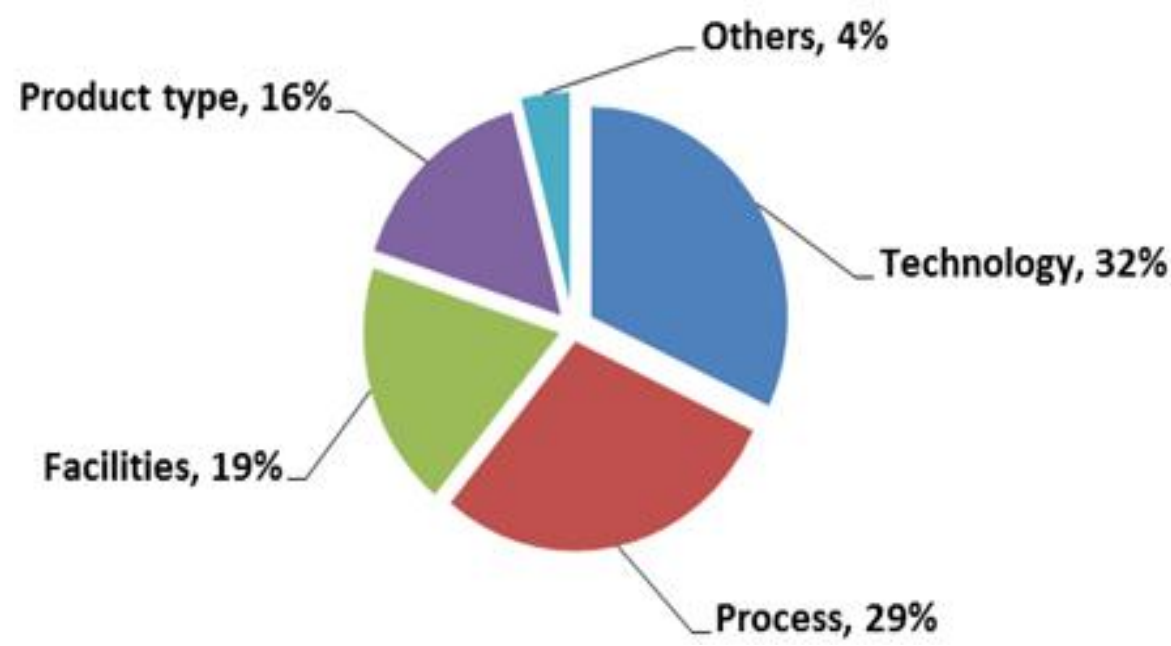

Figure-1. Layout Design Factors.

From the results of observation and secondary data collection, there are four main factors that determine the production performance of an SME. The factor with the highest score is a technological factor, is a factor that highly considered when the company will layout the factory. The technology factor (32\%) is related to the type of technology used, the size of the machinery and equipment to be installed on the factory floor, the nature of the equipment, the technology durability of weather changes, and the dynamics of future technological changes. Meanwhile, Stevenson (2009) divides technology related layout into 3 types, namely: product and services technology, process technology, and information technology.

The second factor - the process with a percentage of $29 \%$, is a factor determining the extent to which the layout will be effectively associated with the stages of the production process that must be done by a factory to produce a good. The more stages to do, the more space will need in the layout. In addition, the more complex a process, then the planned layout will also be more complex as well. Stevenson (2009) also noted five type of processing factors in layout design: job shop, batch, repetitive, continuous, and project. The chosen kind of process that implemented by one factory also will affecting the effectivity of layout and will impact the factory performance.

The third factor is facilities (19\%). Unlike technology in the first factor, facilities factor deals with the configuration of tools and machinery used in a factory layout. The configuration of these tools and machines is primarily intended to smooth out the movement and flow of goods generated from one process to the next. Stevenson (2009) stressed the several basic objectives of this facilities configurations are to avoid production bottlenecks, eliminate unnecessary movement, shorten production time, minimizing material handling costs, and for having safe and secure working conditions.

The fourth factor is product type (16\%). This factor, although as based on observations is ranked on number four, the product type determines the other three factors: technology, process, and facilities used. The product types in Indonesian SMEs are varied, ranging from handicrafts, packaged foods, clothing, home appliances, cosmetics, accessories, seminar supplies, stationeries, and others. The product type, in turn, will greatly affect the layout design used by a manufacturer. However, in most home industries in Indonesia, the chosen type of product produced is one type only. Other finding factors that also considered by operation managers in their SME's factory layout generally relate to the factory location factor. Some of these factors include the availability of adequate raw materials, environmental safety, and transportation. In addition, the human and capital factors are also another consideration in the factory layout in SME.

Furthermore, the four factors above are then derived into appropriate criteria that can be applied to Indonesian SMEs as seen in the following table.

Table-1. Appropriate Criteria for Layout Factors.

\begin{tabular}{l|l}
\hline Factor & Criteria \\
\hline \multirow{4}{*}{ Technology } & 1. Congruity of technology cost with gained benefit \\
\cline { 2 - 2 } & 2. Speed in goods processing \\
\cline { 2 - 2 } & 3. Availability of technology operator \\
\cline { 2 - 2 } & 4. Ease of maintenance \\
\cline { 2 - 2 } & 5. Flexibility to the changes of goods demand \\
\cline { 2 - 2 } & 6. The ratio of the volume of the machine compared to available space \\
\hline \multirow{4}{*}{ Process } & 1. The complexity of the process \\
\cline { 2 - 2 } & 2. Procedure and working time standards \\
\cline { 2 - 2 } & 3. The presence of crossed activities \\
\hline
\end{tabular}




\begin{tabular}{|c|c|}
\hline Factor & Criteria \\
\hline & 4. Nature of activity (goods or job transfer) \\
\hline & 5. A break among job activities \\
\hline & 6. Ease of controlling and supervision process \\
\hline \multirow{5}{*}{ Facilities } & 1. Machines used type (manual, mechanical, or automatic) \\
\hline & 2. Number and capacity of used machines and tools \\
\hline & 3. Production target \\
\hline & 4. Utility availability (electricity, water, a telephone network, etc.) \\
\hline & 5. Space size and the insulation and separation possibility \\
\hline \multirow{5}{*}{ Product Type } & 1. Business type \\
\hline & 2. Nature of finished goods (liquid, solid, gas) \\
\hline & 3. Goods durability \\
\hline & 4. Environment and working atmosphere impact to finished goods \\
\hline & 5. Diversity and product innovation \\
\hline
\end{tabular}

Table 1 shows 22 criteria to be considered for layout the SME's factory, consisting of 6 criteria for technology, 6 criteria for the process, 5 criteria for facilities, and 5 criteria for the product type. The discussion will be focused on efforts to improve production performance through an emphasis on several criteria for each factor.

Technology. Most of Indonesian SMEs use outdated technology or unsupportive technology that lead to production process ineffectiveness. Of course this must be fixed by replacing the existing machines that will increase the speed of their production (criterion 2) and providing the appropriate workforce as the technology operators (criterion 3), as well as the ease of maintenance (criterion 4), and the flexibility to the changes of goods demand (criterion 5). However, the classical Indonesian SMEs constraint is the lack of funding. Thus the first criterion -the congruity of technology cost with gained benefit, will only be really useful when SMEs have replaced the technology. However, this criterion can still be used, as a consideration when the company will replace the technology, i.e. how far the benefits obtained compared to the price of the new technology. The last criterion for Indonesian SMEs, which actually also a classic problem, is the ratio of the volume of the machine compared to available space. This should be answered because in general, the available space of Indonesia SMEs is very limited, and it allocates most for the production process, by negating the room for inventory warehouse and the quality control area. So it is not surprising that the production result is below the level of quality standard.

Process. The complexity of the process is the first criterion to consider when doing a re-layout, although SME's real production activities are not too complicated. However, some types of industries have uniqueness in its processing. This first criterion also relates to a procedure and working time standards (criterion 2) and the existence of activities which work layout is crossed (criterion 3), that has an accident possibility when not fixed. Another criterion that is also considered is the nature of the activity (criterion 4)., where attempts are made that the displacement is the goods, not the people so that the rest time becomes optimal, and no longer needed a long time to rest (criterion 5). Furthermore, this criterion is also related to the ease of controlling and supervision process (criterion 6).

Facilities. The first criterion to be considered in the facilities factor is the type of machine used, whether production manually, mechanically, or automatically. Although in general SME in Indonesia still use manual machines, or if there is a mechanical or automatical machine, but still at the stage of early machine technology. This criterion also relates to how much machines that should be used and its capacity for producing goods (criterion 2) that can fulfill the target of production (criterion 3). Specific for Indonesian SMEs the utility availability (criterion 4) also become a crucial consideration, due to some area in West Java region are lack of electricity, or telephone network, and also the provision of clean water. For the last criterion on this third factor is related to space size and the insulation and separation possibility. It is intended to anticipate changes in the sequence of production processes so that existing layouts can be flexible for future adjustments.

Product Type. This factor has five consideration criteria related to business type. This first criteria such as food production, clothing, handy craft, and others will be a major consideration in the determination of the factory layout. This fourth factor is also determined by the nature of finished goods (criterion 2), whether liquid, solid, or gas, and also influenced by the durability of the product, damage or become obsolete (criterion 3). Environment and working atmosphere related to finished goods become the fourth criteria, as a good environment will affect the quality of the resulting product, and this is determined from the proper layout setting. The final criterion of diversity and product innovation is related to the flexibility of the layout chosen in producing products according to changes and variations in consumer demand.

\section{Conclusions and Recommendations}

Indonesian SMEs layout condition is still in poor condition. This is shown by four important factors affecting company's production performance that related to the layout design, i.e.: technology, process, 
facilities, and product type. The four factors which then equipped with 22 criteria to be considered in designing SME's factory layout, consisting of 6 criteria for technology, 6 criteria for the process, 5 criteria for facilities, and 5 criteria for the product type are also still in a very poor condition, and need to be rearranged in order to improve the company's production performance.

Further research can be continued by deepening each of the generated criteria or research in their application in the specific SME as confirmation stages for the result, so it can reflect the conditions of SME's production layout in Indonesia. Thus the ultimate objective in doing layout such: more effective in using a space, more secure and efficient in equipment and human flow, and healthier working conditions can be easily achieved, and eventually, will enhance the production performances.

\section{References}

Azis, A. M. (2011). Knowledge-based performance management system design for the faculty of business and management. Paper presented at the Proceeding of the 3rd Indonesia International Conference on Innovation Entrepreneurship and Small Business, Bandung Indonesia.

Azis, A. M., \& Azis, Y. (2013). Foundation and basic information in designing performance management system. International Journal of Innovations in Business, 2(4), 327-349.

Azise, A. M., Simatupang, T. M., Wibisono, D., \& Basri, M. H. (2013). Benchmarking criteria and adoption in designing business school's performance management system. Journal of Technology (Humanika Science), 64(3), 49-54.

Belic, D., Kunica, Z., Opetuk, T., \& Dukic, G. (2018). Optimization of the plant layout in the production of the special transformers- case study. FME Transactions, 46(2), 285-290.

Benabes, J., Poirson, E., \& Bennis, F. (2013). Integrated and interactive method for solving layout optimization problems. Expert Systems with Applications, 40(15), 5796-5803.

Bhowmik, R. (2008). An approach to the facility layout design optimization. International Journal of Computer Science and Network Security, 8(4), 212-220.

Chikwendu, O. C., \& Okechukwu, C. (2016). Plant layouts' analysis and design. International Journal of Advanced Engineering Technology, 7(2), 201-206.

Corry, P., \& Kozan, E. (2004). Ant colony optimisation for machine layout problems. Computational Optimization, and Applications, 28(30), 287-310.

De Carlo, F., Arleo, M. A., Borgia, O., \& Tucci, M. (2013). Layout design for a low capacity manufacturing line: A case study. International Journal of Engineering Business Management, Special Issue on Innovations in Fashion Industry, 5(Godište 2013), 1-10.

Dias, L., Pereira, G., Vik, O., \& Oliveira, J. (2012). Integrated design of production systems in a lighting manufacturer - using CAD and simulation in layout and process optimization. Paper presented at the Proceeding of CLAIO SBPO, Rio de Janeiro Brazil, September 24-28.

Drira, A., Pierreval, H., \& Hajri-Gabouj, S. (2007). Facility layout problems: A survey. Annual Reviewes in Control, 31(2), 255-267.

Fei, M. Y., Feng, Z., D., \& Xia, L. Q. (2011). Study on performance-based safety design of chemical facility layout. Procedia Engineering, 11, 319-324.

Fitriani, A., Prakoso, G., \& Azis, A. M. (2015). Facility layout improvement: Based on safety and health at work and standards of food production facility. Paper presented at the International Conference on Trends in Economics, Humanities, and Management, March 27-28 2015 Singapore.

Irjayanti, M., \& Azis, A. M. (2013). Success factors of fast moving goods of small medium enterprises in Indonesia. Journal of Global Entrepreneurship, 4(1), 17-30.

Irjayanti, M., Azis, A. M., \& Sari, P. A. (2016). Indonesian SMEs readiness for ASEAN economic community. Actual Problems of Economics, 177, 31-38.

Irjayantis, M., \& Azis, A. M. (2017). Implementing technology in creative industry (Benchmarking Study in Developed Countries). Advanced Science Letters, 23(9), 8113-8118.

Kareem, B., Oke, P. K., \& Lawal, A. S. (2013). Development of a flexible process layout for A Nigerian beverage industry. Research in Logistics and Production, 3(1), 37-47.

Khan, A. J., \& Tidke, D. J. (2013). Designing facilities layout for small and medium enterprises. International Journal of Engineering Research and General Science, 1(2), 1-8.

Kovacs, G., \& Kot, S. (2017). Facility layout redesign for efficiency improvement and cost reduction. Journal of Applied Mathematics and Computational Mechanics, 16(1), 63-74.

Kumar, V., Verma, P., Onkar, Singh, S. P., \& Katiyar, J. (2016). Facility and process layout analysis of an SME using simulation: A case study of a manufacturing company. Paper presented at the Proceedings of the 2016 International Conference on Industrial Engineering and Operations Management Kuala Lumpur, Malaysia, March 8-10, 2016.

Modrak, V., Soltysova, Z., \& Bednar, S. (2017). Performance evaluation of layout-designs by throughput rate and operational complexity. Procedia CIRP, 62, 175-180.

Naik, B. S., \& Kallurkar, S. A. (2016). A literature review on efficient plant layout design. International Journal of Industrial Engineering Research and Development, 7(2), 43-51.

Ojaghi, Y., Khademi, A., Yusof, N. M., Renani, N. G., \& Syed-Helmi, S. A. (2015). Production layout optimization for small and medium scale food industry. Procedia CIRP, 26, 247-251.

Ramli, R., \& Chen, K. M. (2014). A combined approach of simulation and analytic hierarchy process in assessing production facility layouts. Paper presented at the AIP Conference Proceedings.

Sharma, P., Singh, R. V., \& Singhal, S. (2013). A review of meta-heuristic approaches to solve facility layout problem. International Journal of Emerging Research in Management ${ }^{\circ}$ Technology, 2(10), 29-33. 
Silva, J. F., Mendes, J. F. G., \& Ramos, R. A. R. (2016). Assesment of lot layout and coverage in business park design. Procedia Engineering, 161, $2062-2067$.

Singh, P., \& Singh, M. (2015). Optimization of assembly line and plant layout in a mass production industry-a literature survey. International Journal of Engineering Science Invention, 4(4), 1-4.

Stevenson, W. J. (2009). Operation management (10th ed.). NY: McGraw-Hill, Irwin.

Susanto, R. J., \& Azis, A. M. (2017). Inventory management training and layout of the small business processing of brick making in the village of Ciseupan, Cimahi City. Dharma Bhakti Ekuitas Journal, 2(1), 154-158.

Tao, J., Wang, P., Qiao, H., \& Tang, Z. (2012). Facility layouts based on intelligent optimization approaches. Paper presented at the IEEE 5th International Conference on Advanced Computational Intelligence, China.

Tasadduq, I. A., Imam, M. H., \& Ahmad, A. (2015). A hybrid algorithm for optimising facility layout. South African Journal of Industrial Engineering, 26(1), 120-134.

Vasconcelos, B., \& Junior, B. B. (2015). The causes of workplace accidents and their relation to construction equipment design. Procedia Manufacturing, 3, 4392-4399.

Yin, R. K. (2014). Case study research: Design and methods (5th ed.). Los Angeles: Sage.

Zakaria, N. H., Mansor, N., \& Abdullah, Z. (2012). Workplace accident in Malaysia: Most common causes and solutions. Business and Management Review, 2(5), 75-88. 